\title{
The Tall Docks of Saskatchewan
}

\author{
ARCH C. BUDD
}

In Saskatchewan we have three docks growing to a height of three feet or more which are difficult to distinguish at first sight. They all produce a copious amount of fruit and are very conspicuous in late summer when they turn a dark brown color and are seen standing erect in fields and waste places. These are the native Western dock, (Rumex occidentalis) and two introduced species, Curled dock, (Rumex crispus) and Field dock, (Rumex domesticus). The distinguishing features are the shape and form of the leaves, the presence or absence of a small swollen joint near the base of the stalk of the individual fruits, and the presence or absence of small grain-like tubercles in the valves or outer sepals of the fruit.

The following key may prove useful:-

1. Fruiting valves each with a tubercle; fruiting stalk with an enlarged joint; leaves strongly wavy and curly on the margins.

(1) Rumex crispus. Fruiting valves with no tubercles or only one.

2. Stalks of fruit with an enlarged joint; sometimes with one small tubercle in valve; leaves tapering to the base.

(2)Rumex domesticus. Stalks of fruit without an enlarged joint; no tubercle in valve; leaves tapering at base.

(3) Rumex occidentalis.

(1) Curled dock is an introduced weed, somewhat sparingly distributed throughout the west and found in low places, slough margins, moist farm yards ete.

(2) Field dock is also an introduced weed, first reported near Wymark in 1942. It is spreading very rapidly in many parts of the province and is probably the most abundant dock in many areas. Whilst formerly found principally or the lands it is now invading the low areas and is competing there with the Western dock. Large quantities of it have been noticed this year on the Regina plains, north to Davidson and all through the south-western part of the province. Its potentially as a bad weed is apparent by its rapid spread, its copious seed production and the fact that it is invading upland grain fields.

(3) Western dock is a native plant and appears to be confined to the permanently moist lands, stream banks, drainage basins and marshy areas.

The new slate of officers and directors elected at the meeting are printed on the back cover.

\section{An Albino Sparrow}

By Chas. F. Southey, Young, Sask.

In the early part of May, 1953 a neighbour of mine, Mr. George Schatz, noticed an albino in a flock of sparrows which stayed around his garden for a day.

This year only about fifty yards away I saw an albino in a flock of sparrows but was unable to tell what variety.

I don't think that there is any doubt that it was the same bird, showing how closely these flocks follow the same path under ordinary conditions.
However on certain days this last spring, weather conditions certainly did tend to affect the migrating flights.

The most noticeable one here was a very large flock of Ruby-crowned Kinglets forced to come down during the late snowstorm and many perished.

This is the first time in forty-five years that I have seen a large flock of kinglets in this locality ... all I have seen previously have been just odd stragglers. 